\title{
Benzyl Nicotinate as an Efficient Corrosion Inhibitor for Cold Rolled Steel in a 1 M HCl Solution
}

\author{
M.R. Vinutha, ${ }^{a}$ T.V. Venkatesha, ${ }^{a,}{ }^{*}$ and Vinayak Bhat $^{b}$ \\ ${ }^{a}$ Department of Chemistry, School of Chemical Science, Jnana Sahyadri Campus, Kuvempu \\ University, Shankaraghatta-577451, Karanataka, India \\ ${ }^{b}$ Department of Physics, Shri Madhwa Vadiraja Institute of Technology and Management, \\ Bantakal, Udupi-574115, India
}

Received August 27, 2016; accepted April 02, 2017

\begin{abstract}
The ability of benzyl nicotinate $(\mathrm{BN})$ to inhibit the corrosion process of cold rolled steel (CRS) in a $1 \mathrm{M} \mathrm{HCl}$ solution has been investigated by weight loss measurements, potentiodynamic polarization and electrochemical impedance spectroscopic methods. The potentiodynamic polarization study revealed that $\mathrm{BN}$ acts as a mixed type inhibitor. The effect of temperature range $(303-333 \mathrm{~K})$ on the corrosion of steel was studied at different concentrations of BN. The efficiency of this inhibitor increases with an increase in its concentration, and decreases with rise of temperature. Free energy values revealed that $\mathrm{BN}$ molecule undergoes comprehensive adsorption. The adsorptive behavior of BN on CRS obeys Langmuir adsorption. The thermodynamic and activation parameters calculation helped in getting insight into the inhibitor mechanism. The DFT (density functional theory) studies of $\mathrm{BN}$ molecule also supported our experimental findings.
\end{abstract}

Keywords: BN, corrosion, EIS, quantum studies.

\section{Introduction}

Hydrochloric acid is widely used as pickling liquor for processes like descaling, pickling, acid cleaning and oil-well acidizing, etc. Steel (mild steel-MS, cold rolled steel-CRS, and stainless steel-SS) of various forms is employed in all industries for many purposes, such as storage tanks, containers, boilers, carrier pipes, etc. But, during its surface treatment, steel gets damaged due to the corrosive nature of acid solution, thereby reducing its service life. This corrosive damage occurs as a result of electrochemical reactions at the surface, which cause the failure of materials [1]. To avoid this, various preventive methods were developed by the researchers, and the use of corrosion inhibitors is one of the best practical methods.

\footnotetext{
* Corresponding author. E-mail address: drtvvenkatesha@yahoo.co.uk
} 
Corrosion inhibitors are organic compounds containing heteroatoms like $\mathrm{P}, \mathrm{S}, \mathrm{O}$ and $\mathrm{N}$ in their ring structure, which show good corrosion inhibition properties in acidic media [2-8]. Inhibitors act through the process of adsorption, and their adsorptive nature depends upon the electronic density at the donor site, aromaticity, steric factor, molecular mass, presence of functional groups like $\mathrm{C}=\mathrm{O},-\mathrm{N}=\mathrm{N}-,-\mathrm{OH},-\mathrm{COOR}$, temperature and potential developed at the metal solution interface. Literature survey reveals that derivatives of Schiff bases, triazoles, thiozoles, pyridine and many other organic compounds were reported as good corrosion inhibitors in acidic media [9-12]. A few researchers have reported the use of nicotinic acid derivatives, namely, M.P. Chakravarthy et al. [13-14], which have studied the inhibitive effect of two nicotinamide derivatives and two isonicotinic acid derivatives of indole and pyrrol on mild steel in $0.5 \mathrm{M}$ $\mathrm{HCl}$. The anti-corrosive effect using nicotinic acid hydrazide and its benzalidine derivatives as inhibitors in a $1 \mathrm{M} \mathrm{HCl}$ solution studied by Hemapriya et al. [15] showed a as high as 90\% and 94\% inhibition efficiency, respectively. Jun Zhao et al. [16] have used cigarette butts as a corrosion inhibitor for $\mathrm{N} 80$ steel in an $\mathrm{HCl}$ solution; they contain nicotine and nicotine derivatives as major components, which show $92 \%$ inhibition efficiency in $5 \%$ by weight of inhibitor solution in $10 \% \mathrm{HCl}$.

The inhibitors containing nicotine heterocycle are less reported in the literature, so we have chosen benzyl nicotinate (BN) (Fig. 1).

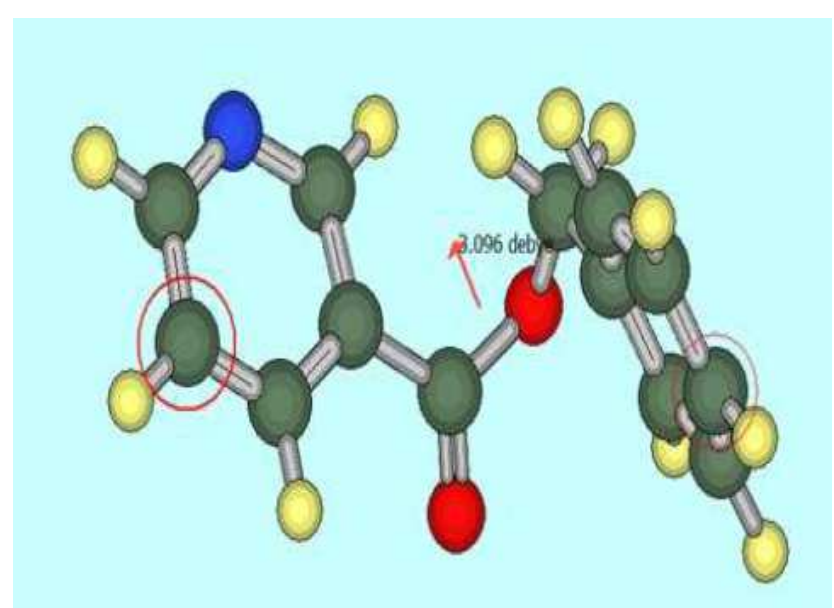

Figure 1. Structure of benzyl nicotinate $(\mathrm{BN})$.

Previously, we have verified the inhibitory effect of BN on the corrosion of CRS in a $0.5 \mathrm{M} \mathrm{H}_{2} \mathrm{SO}_{4}$ solution [17]. In the present work, studies on the theoretical, adsorptive and electrochemical behavior of $\mathrm{BN}$ on the corrosion of CRS in a $1 \mathrm{M}$ $\mathrm{HCl}$ solution are evaluated.

\section{Experimental}

\section{Sample}

The experiments were performed with CRS specimens with the compositions of $0.14 \% \mathrm{C}, 0.4 \% \mathrm{Mn}, 0.025 \% \mathrm{P}, 0.0008 \% \mathrm{~S}, 0.025 \% \mathrm{Si}, 0.003 \% \mathrm{Al}$ and remaining of Fe. 


\section{Solutions}

The aggressive solutions of $1 \mathrm{M} \mathrm{HCl}$ AR-grade were prepared using double distilled Millipore water. The tested inhibitor benzyl nicotinate (BN) of AR grade was purchased from Sigma-Aldrich Chemicals, Bangalore. The different concentrations of inhibitor ( 0 to $500 \mathrm{ppm}$ ) were prepared in a $1 \mathrm{M} \mathrm{HCl}$ solution.

\section{Weight loss measurement}

The CRS coupons of dimension $4 \mathrm{~cm} \times 2 \mathrm{~cm} \times 0.5 \mathrm{~cm}$ were used for weight loss measurements. The coupons were treated with a series of emery paper from 220 , $330,400,600$ and 1200 grades to obtain a uniform surface. Then, the specimens were washed several times with distilled water, then with acetone, and dried using a stream of air. The weight loss incurred by CRS specimens was determined by weighing the samples before and after immersion in $100 \mathrm{~cm}^{3}$ of 1 $\mathrm{M} \mathrm{HCl}$, in the absence and presence of various concentrations of $\mathrm{BN}$ at different temperature ranges of $303,313,323$, and $333 \mathrm{~K}$. The experiments were performed in triplicate and the mean value is reported. The experiments were carried out in a static aerated condition. The corrosion rate $\left(v_{\text {corr }}\right)$ of CRS was determined using the following relation:

$$
\boldsymbol{V}_{\text {corr }}=\frac{\Delta m}{S t}
$$

where $v_{\text {corr }}$ is the corrosion rate of mild steel $\left(\mathrm{g} \mathrm{cm}^{-2} \mathrm{~h}^{-1}\right), \Delta m$ is the corrosion weight loss of mild steel $(\mathrm{g}), S$ is the surface area of mild steel specimen $\left(\mathrm{cm}^{2}\right)$, and $t$ is the time of exposure. The percentage inhibition efficiency was calculated using the relationship:

$$
\% I E=\frac{V_{c o r r}^{o}-V_{c o r r}}{V_{c o r r}^{o}} \times 100
$$

where $v_{\text {corr }}^{0}$ and $v_{\text {corr }}$ are the corrosion rates of CRS in the absence and presence of $\mathrm{BN}$, respectively.

\section{Electrochemical measurements}

Electrochemical measurements were conducted in a conventional glass cell using a CHI 660D electrochemical analyzer (USA made). The CRS specimen of $1 \mathrm{~cm}^{2}$ exposed areas with a $5 \mathrm{~cm}^{2}$ long stem isolated with araldite resin was used as working electrode; platinum electrode and calomel electrode were used as counter and reference electrodes, respectively. Prior to polarization and electrochemical impedance spectroscopic measurements (EIS), a steady state open circuit potential (OCP) was measured. Each experiment was carried out in triplicate and the average values of corrosion parameters were reported.

EIS measurements were done at OCP in the frequency range from $100 \mathrm{kHz}$ to $0.01 \mathrm{~Hz}$, with an amplitude of $5 \mathrm{mV}$. The inhibition efficiency of EIS measurements was calculated using charge transfer resistance $\left(R_{c t}\right)$ values by the following equation: 


$$
\% I E_{(i m p)}=\frac{R_{c t}-R_{c t}^{o}}{R_{c t}} \times 100
$$

where $R_{c t}$ and $R_{c t}^{0}$ are charge transfer resistance of the working electrode with and without inhibitor, respectively.

Polarization plots were automatically obtained in a potential range from -1000 $\mathrm{mV}$ to $-200 \mathrm{mV}$ with a scan rate of $10 \mathrm{mV} / \mathrm{S}$. Corrosion parameters like corrosion current density ( $\left.\mathrm{I}_{\mathrm{corr}}\right)$, equilibrium potential $\left(\mathrm{E}_{\mathrm{corr}}\right)$, cathodic $\left(\beta_{\mathrm{c}}\right)$ and anodic $\left(\beta_{\mathrm{a}}\right)$ Tafel slopes were calculated. Inhibition efficiency of polarization method was calculated using the corrosion current density values by the following relation:

$$
\% I E_{(p o l)}=\frac{I_{c o r r}^{o}-I_{\text {corr }}}{I_{\text {corr }}^{o}} \times 100
$$

where $\mathrm{I}_{\text {corr }}^{0}$ and $\mathrm{I}_{\text {corr }}$ are the corrosion current density in the absence and presence of the inhibitor, respectively.

\section{Quantum and SEM studies}

In the present study, quatum calculations were performed using pc gamess (firefly) software by DFT method using B3LYP/6-311 G basic set. The surface morphology of cold rolled steel samples is investigated using Scanning electron microscopy.

\section{Results and discussion}

\section{Polarization studies}

The anodic and cathodic polarization plots for CRS in $1 \mathrm{M} \mathrm{HCl}$ at various concentrations of BN are as shown in Fig. 2.

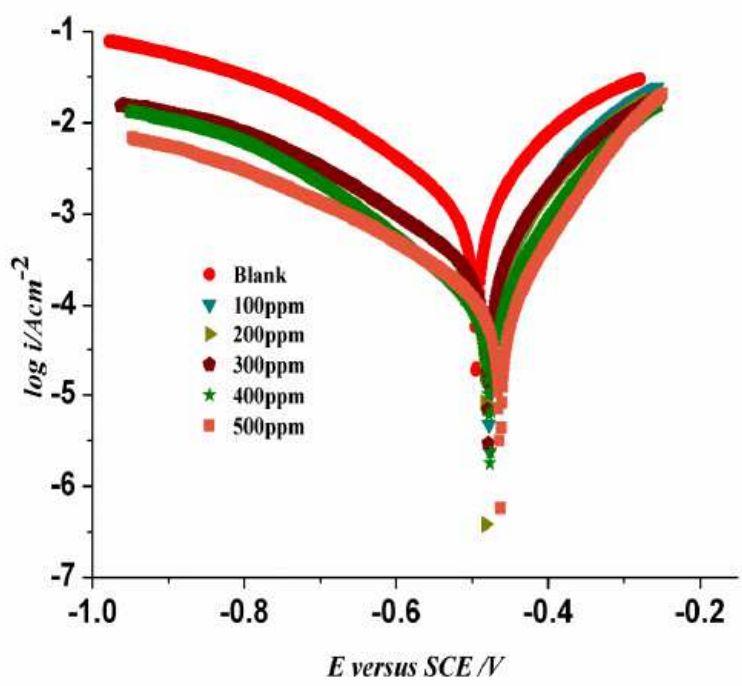

Figure 2. Potentiodynamic polarization response of various concentrations of $\mathrm{BN}$ in a 1 $\mathrm{M} \mathrm{HCl}$ solution. 
The values of corrosion current density $\left(\mathrm{I}_{\mathrm{corr}}\right)$, corrosion potential $\left(\mathrm{E}_{\mathrm{corr}}\right)$, cathodic $\left(\beta_{\mathrm{c}}\right)$ and anodic $\left(\beta_{\mathrm{a}}\right)$ Tafel slopes, and inhibition efficiency (IE), as a function of $\mathrm{BN}$ concentrations, are tabulated in Table 1. From the table it is indicated that the corrosion current density, $\mathrm{I}_{\text {corr }}$, considerably decreases with an increase in the concentrations of BN. We can classify the inhibitor as of the anodic or cathodic type if the change in the $\mathrm{E}_{\text {corr }}$ value is above $85 \mathrm{mV}$ [20]. But, in the present study, the maximum obtained shift in $\mathrm{E}_{\text {corr }}$ value was $32 \mathrm{mV}$. On the other hand, changes in cathodic $\left(\beta_{\mathrm{c}}\right)$ and anodic $\left(\beta_{\mathrm{a}}\right)$ slope values with $\mathrm{BN}$ concentrations revealed that $\mathrm{BN}$ controls both anodic steel dissolution reactions and cathodic hydrogen evolution reaction. Hence, we can arrive at the conclusion that $\mathrm{BN}$ acts as a mixed type inhibitor.

Table 1. Electrochemical polarization parameters of CRS at a $1 \mathrm{M} \mathrm{HCl}$ solution in absence and presence of $\mathrm{BN}$ measured at $303 \mathrm{~K}$.

\begin{tabular}{cccccc}
\hline $\begin{array}{c}\text { Concentration } \\
(\mathbf{p p m})\end{array}$ & $\begin{array}{c}-\mathbf{E}_{\text {corr }} \\
(\mathbf{m V})\end{array}$ & $\begin{array}{c}\boldsymbol{\beta}_{\mathbf{c}} \\
\left(\mathbf{m V d e c}^{-\mathbf{1}}\right)\end{array}$ & $\begin{array}{c}\boldsymbol{\beta}_{\mathbf{a}} \\
\left(\mathbf{m V d e c}^{-\mathbf{1}}\right)\end{array}$ & $\begin{array}{c}\mathbf{I}_{\mathbf{c o r r}} \\
\left(\mathbf{m A c m}^{-2}\right)\end{array}$ & $\begin{array}{c}\text { IE } \\
(\mathbf{\%})\end{array}$ \\
\hline Blank & 495 & 156.7 & 120.9 & 1.2 & - \\
100 & 482 & 168.1 & 86.9 & 0.22 & 82 \\
200 & 479 & 176.4 & 95.2 & 0.18 & 85 \\
300 & 477 & 175.9 & 99.7 & 0.15 & 88 \\
400 & 477 & 148.3 & 84.3 & 0.1 & 92 \\
500 & 463 & 164.4 & 81.6 & 0.09 & 93 \\
\hline
\end{tabular}

\section{Electrochemical impedance spectroscopic studies}

Electrochemical impedance spectroscopic technique is a widely used method for investigating corrosion phenomena. It gives complete information of both capacitive and resistive behavior of the metal/solution interface. The effect of different concentrations of $\mathrm{BN}$ on the impedance behavior of $\mathrm{CRS}$ in a $1 \mathrm{M} \mathrm{HCl}$ at room temperature is exhibited by the Nyquist plot, as shown in Fig. 3. The extracted impedance data are analyzed using ZSimpWin-3.21 software by fitting to a suitable circuit (as in Fig. 4), and the corresponding EIS values are tabulated in Table 2. In the circuit, $R_{s}$ stands for solution resistance, $R_{c t}$ is charge transfer resistance and $\mathrm{Q}$ is a constant phase element is CPE. CPE is composed of $\mathrm{Q}_{\mathrm{dl}}$ and coefficient $n$, where $n$ represents surface in-homogeneity, roughness, and porous layer formation [21]. The double layer capacitance $\left(\mathrm{C}_{\mathrm{dl}}\right)$ is calculated by the relation:

$$
C_{\mathrm{dl}}=\left(Q R_{\mathrm{ct}}^{1-\mathrm{n}}\right)^{1 / \mathrm{n}}
$$

The Nyquist plot at all concentrations nearly shows the same behavior, indicating that a semicircle at a higher frequency is related to charge transfer process. A small inductive loop observed at a low frequency is attributed to the relaxation process obtained by the adsorption of the inhibitor molecule on the electrode surface or by the adsorption of species like $\left(\mathrm{FeCl}^{-}\right)_{\text {ads }}$ or $\left(\mathrm{FeCl}^{-}{ }_{\text {Inh+ }}\right)_{\text {ads }}$ [22]. It may also be due to the re-dissolution of adsorbed species [23]. 


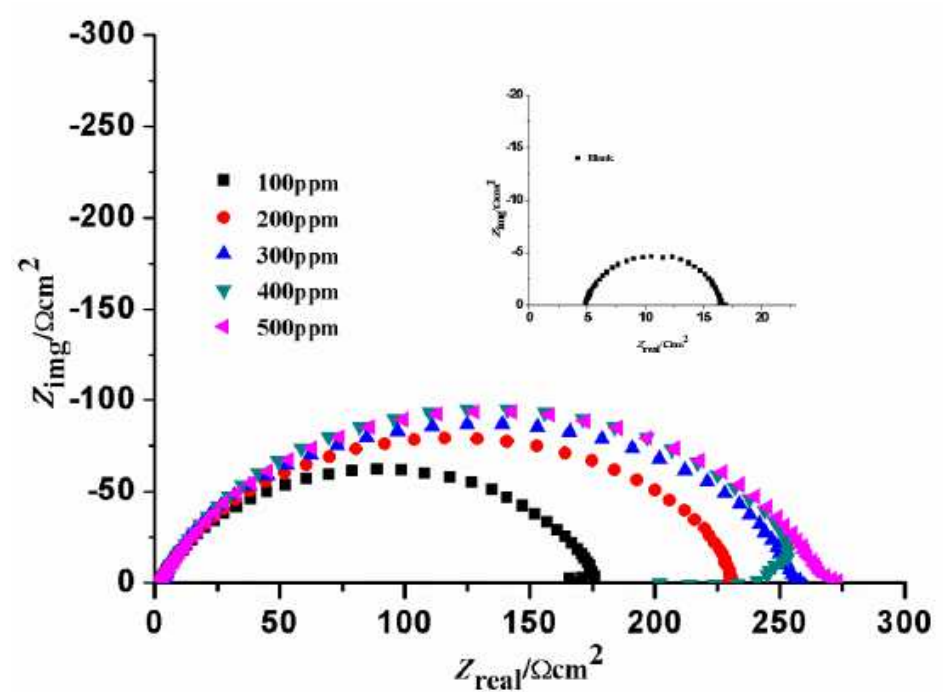

Figure 3. EIS plots for different concentrations of $\mathrm{BN}$ in a $1 \mathrm{M} \mathrm{HCl}$ solution.

The successive increase in semicircle diameter with an increase in the $\mathrm{R}_{\mathrm{ct}}$ value is attributed to the increase of corrosion resistance of CRS in presence of different concentrations of inhibitor [24]. The decreasing value of $\mathrm{C}_{\mathrm{dl}}$ showed a decrease in local dielectric constant, due to an increase in the thickness of the protective double layer at the CRS surface, because of the inhibitor adsorption.

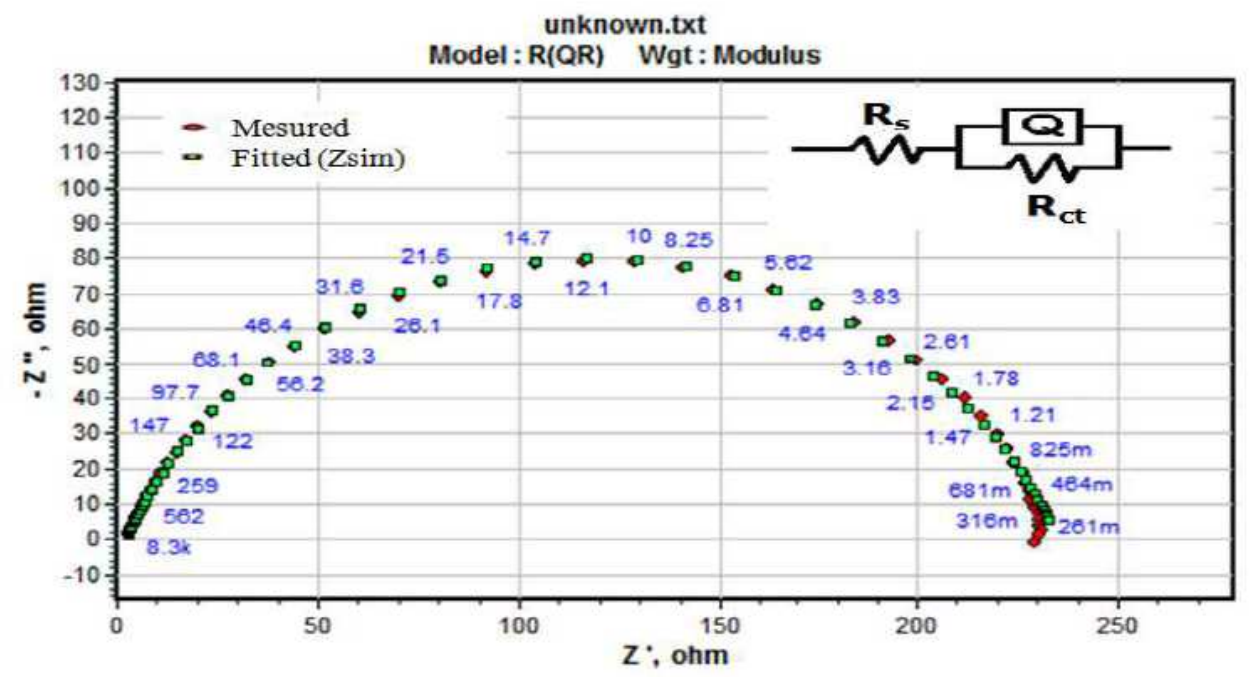

Figure 4. EIS plot of BN fitted to suitable circuit using ZSimpWin-3.21 software.

Table 2. Electrochemical impedance parameters of CRS at $1 \mathrm{M} \mathrm{HCl}$ solution in absence and presence of BN measured at $303 \mathrm{~K}$.

\begin{tabular}{cccccc}
\hline $\begin{array}{c}\text { Concentration } \\
(\mathbf{p p m})\end{array}$ & $\begin{array}{c}\mathbf{R}_{\mathbf{c t}} \\
\left(\mathbf{\Omega} \mathbf{c m}^{-\mathbf{2}}\right)\end{array}$ & $\begin{array}{c}\mathbf{Q} \\
\left(\boldsymbol{\mu} \mathbf{\Omega}^{-\mathbf{1}} \mathbf{S}^{\mathbf{n}} \mathbf{c m}^{-\mathbf{2}}\right)\end{array}$ & $\mathbf{N}$ & $\begin{array}{c}\mathbf{C}_{\mathbf{d l}} \\
\left(\boldsymbol{\mu} \mathbf{F} \mathbf{c m}^{-\mathbf{2}}\right)\end{array}$ & $\begin{array}{c}\mathbf{I E} \\
(\mathbf{\%})\end{array}$ \\
\hline Blank & 12.4 & 269.6 & 0.8513 & 11.24 & - \\
100 & 195.2 & 141.5 & 0.8083 & 60.40 & 93.6 \\
200 & 232.7 & 157.6 & 0.7674 & 57.86 & 94.7 \\
300 & 275.1 & 137.3 & 0.7621 & 49.38 & 95.5 \\
400 & 355.3 & 105.9 & 0.8108 & 49.26 & 96.5 \\
500 & 357 & 125.1 & 0.7620 & 47.40 & 96.6 \\
\hline
\end{tabular}


Table 3. Corrosion rate and the inhibition efficiencies in a $1 \mathrm{M} \mathrm{HCl}$ solution at different temperatures at various concentrations of $\mathrm{BN}$, as obtained from weight loss measurements.

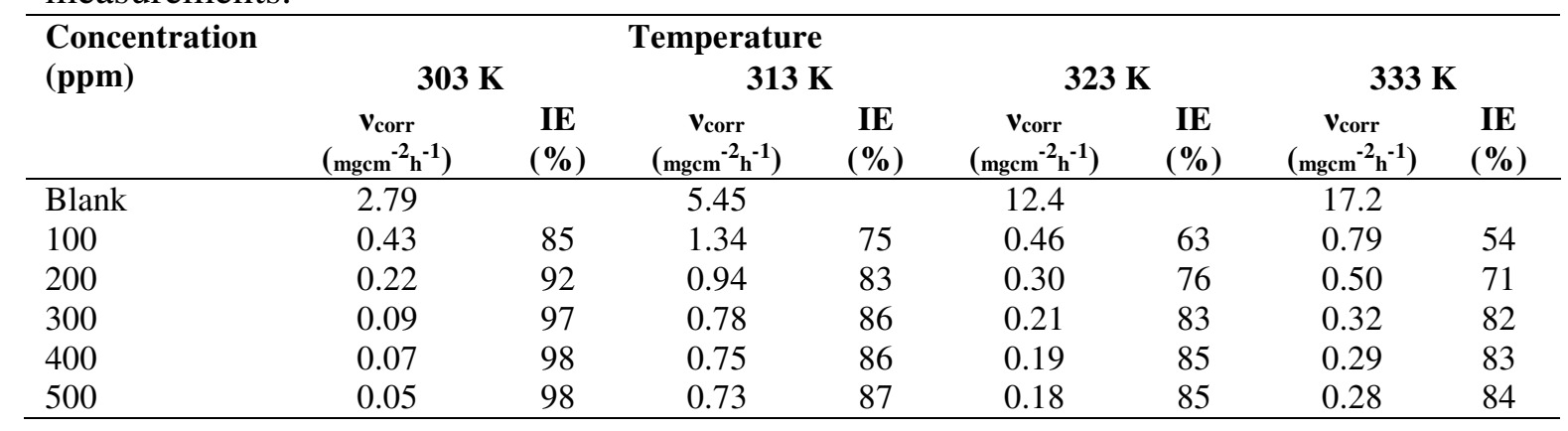

\section{Weight loss measurements}

The weight loss of CRS specimen in $1 \mathrm{M} \mathrm{HCl}$ is determined in absence and presence of different concentrations of inhibitor at different temperature ranges of $303 \mathrm{~K}$ to $333 \mathrm{~K}$. The corrosion rate and inhibition efficiency values are tabulated in Table 3. From the values, it is revealed that the corrosion rate decreases with an increase in the concentration of inhibitor. This is due to an increase in the surface coverage of steel with an increase in the concentration of inhibitor [19]. Inhibition efficiency increases with an increase in the concentration of inhibitor, and decreases with an increase in temperature, indicating that the adsorption of $\mathrm{BN}$ on CRS is physisorption. The maximum inhibition efficiency was observed at $500 \mathrm{ppm}$ in all temperatures.

\section{Corrosion kinetic parameters}

The effect of temperature on the corrosion parameters of CRS in $1 \mathrm{M} \mathrm{HCl}$ was studied at the temperatures of 303-333 K. Since corrosion is regarded as an Arrhenius process, the Arrhenius plot (Fig. 5), in addition to transition state plots (Fig. 6), was used to obtain corrosion kinetic parameters like pre-exponential factor $(\mathrm{A})$, activation energy $\left(\mathrm{E}_{\mathrm{a}}\right)$, enthalpy of activation $\left(\Delta \mathrm{H}^{*}\right)$ and activation entropy $\left(\Delta S^{*}\right)$ for corrosion of CRS in $1 \mathrm{M} \mathrm{HCl}$, both in absence and presence of $\mathrm{BN}$.

The pre-exponential factor (A) and activation energy $\left(E_{a}\right)$ are obtained from Arrhenius equation [25].

$$
\gamma_{\text {corr }}=A \exp \left(\frac{-E_{a}}{R T}\right)
$$

where $\gamma_{\text {corr }}$ is corrosion current, $\mathrm{R}$ is universal gas constant and $\mathrm{T}$ is temperature measured in K. Taking a logarithm to the equation (6), it gets reduced to:

$$
\ln \left(\gamma_{\text {corr }}\right)=\ln A-\frac{E_{a}}{R T}
$$

The plot of $\ln \left(\gamma_{\text {corr }}\right)$ against $1 / \mathrm{T}$ gives a straight line with a slope of $-\mathrm{E}_{\mathrm{a}} / \mathrm{RT}$ and intercept equal to $\ln (\mathrm{A})$. The values of $\mathrm{E}_{\mathrm{a}}$ and $\mathrm{A}$ were tabulated in Table 4 . The 
changes in enthalpy, $\Delta \mathrm{H}$, and entropy, $\Delta \mathrm{S}$, are calculated using transition state equation [26].

$$
\gamma_{c o r r}=\frac{R T}{N h} \exp \left(\frac{\Delta S^{*}}{R}\right) \exp \left(\frac{-\Delta H^{*}}{R T}\right)
$$

where $\mathrm{N}$ is Avogadro's number and h is Plank's constant. The equation 8 can be reduced to:

$$
\ln \left(\frac{\gamma_{c o r r}}{T}\right)=\frac{-\Delta H}{R T}+\left(\ln \frac{R}{N h}+\frac{\Delta S^{*}}{R}\right)
$$

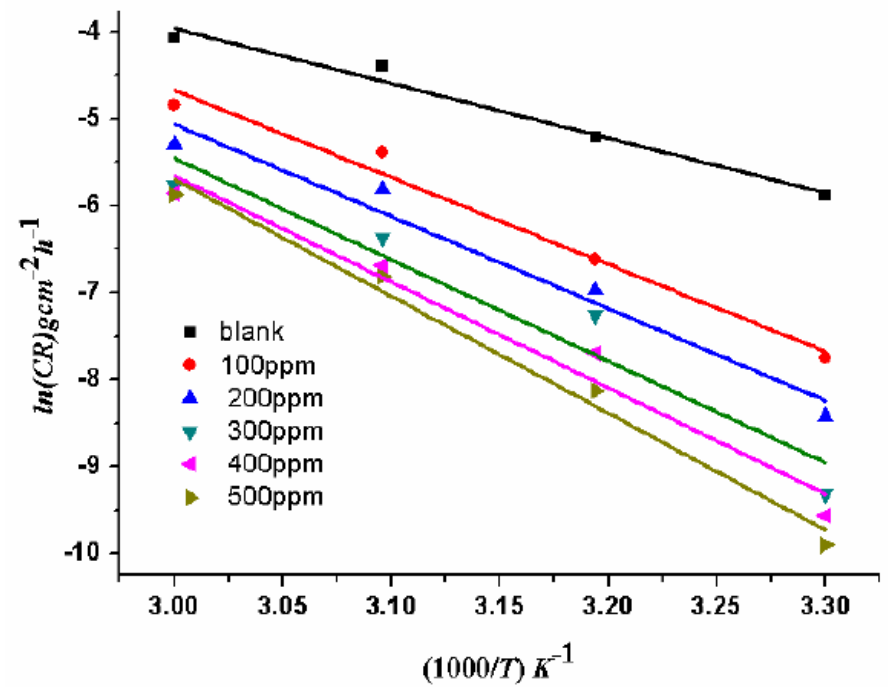

Figure 5. Arrhenius plots for CRS in $1 \mathrm{M} \mathrm{HCl}$ in absence and presence of different concentrations of inhibitor.

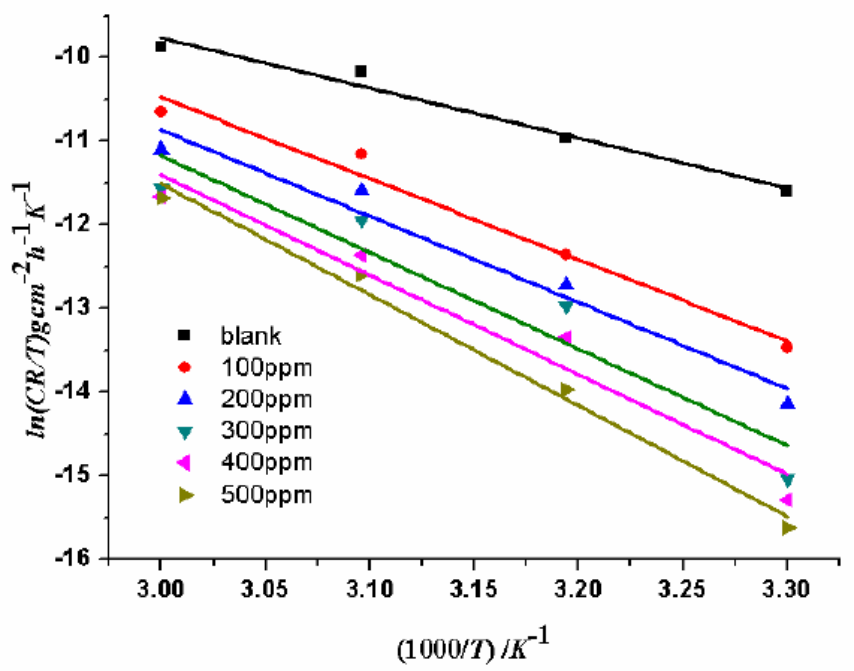

Figure 6. Transition state plots for $\mathrm{CRS}$ in $1 \mathrm{M} \mathrm{HCl}$ in absence and presence of different concentrations of inhibitor.

The graph of $\ln \left(\gamma_{\text {corr }} / \mathrm{T}\right)$ against $1 / \mathrm{T}$ gives a straight line with a slope of $-\Delta \mathrm{H}^{*} / \mathrm{R}$ and intercept of $\ln (\mathrm{R} / \mathrm{Nh})+\Delta \mathrm{S}^{*} / \mathrm{R}$; values of $\Delta \mathrm{H}^{*}$ and $\Delta \mathrm{S}^{*}$ were given in Table 
4. The temperature dependency of inhibition efficiency and $E_{a}$ can be categorized into three groups [27-28].

1. Inhibition efficiency decreases with an increase in temperature, $E_{\mathrm{a}}$ (inhibited solution) $>E_{\mathrm{a}}$ (uninhibited solution)

2. Inhibition efficiency increases with an increase in temperature, $E_{\mathrm{a}}$ (inhibited solution) $<E_{\mathrm{a}}$ (uninhibited solution)

3. Inhibition efficiency does not change with temperature, $E_{\mathrm{a}}$ (inhibited solution $)=E_{\mathrm{a}}($ uninhibited solution $)$.

Table 4. Activation parameters for CRS in a $1 \mathrm{M} \mathrm{HCl}$ solution obtained from weight loss method.

\begin{tabular}{ccccc}
\hline $\begin{array}{c}\text { Concentration } \\
(\mathbf{p p m})\end{array}$ & $\begin{array}{c}\mathbf{A} \\
\left(\mathbf{g c m}^{-\mathbf{2}} \mathbf{h}^{-\mathbf{1}}\right)\end{array}$ & $\begin{array}{c}\mathbf{E}_{\mathbf{a}} \\
(\mathbf{k J m o l} \mathbf{})\end{array}$ & $\begin{array}{c}\mathbf{\Delta} \mathbf{H}^{*} \\
\left(\mathbf{k J m o l}^{\mathbf{- 1}}\right)\end{array}$ & $\begin{array}{c}\mathbf{\Delta \mathbf { S } ^ { * }} \\
\left(\mathbf{J m o l}^{\mathbf{1}} \mathbf{K}^{\mathbf{- 1}}\right)\end{array}$ \\
\hline Blank & $3.065 \times 10^{6}$ & 52.36 & 49.72 & -129.6 \\
100 & $1.034 \times 10^{11}$ & 83.23 & 80.60 & -42.8 \\
200 & $4.151 \times 10^{11}$ & 88.16 & 85.54 & -31.3 \\
300 & $6.875 \times 10^{12}$ & 97.03 & 95.90 & -2.7 \\
400 & $2.775 \times 10^{13}$ & 101.45 & 98.92 & 4.4 \\
500 & $1.156 \times 10^{15}$ & 111.89 & 110.06 & 36.9 \\
\hline
\end{tabular}

In the present case, $E_{a}$ of the inhibited solution is greater than $E_{a}$ of the uninhibited solution, showing that inhibition efficiency decreases with an increase in temperature, indicating physical (electrostatic) adsorption of BN. According to literature, a lower value of pre-exponential factor (A) and a higher value of $E_{a}$ lowers corrosion rate [29]. In the present study, the value of $A$ increases with an increase in concentration of $\mathrm{BN}$. Hence, the corrosion rate entirely depends upon the activation parameter, $E_{a}$. The positive value of $\Delta H^{*}$ indicates the endothermic nature of corrosion, showing the hindrance for steel dissolution [30]. $\Delta \mathrm{H}^{*}$ and $\mathrm{E}_{\mathrm{a}}$ values are nearly the same, and both increase with an increase in the concentrations of inhibitor, indicating a raise in the energy barrier of the corrosion process, without affecting the mechanism of dissolution. It is observed that $\mathrm{E}_{\mathrm{a}}-\Delta \mathrm{H}^{*}=\mathrm{RT}$ is indicative of uni-molecular adsorption of $\mathrm{BN}$ molecules [31]. The value of $\Delta \mathrm{S}^{*}$ increases with an increase in the concentrations of inhibitor, showing that the free energy of reactants is converted into an activated complex [32]. The adsorption of $\mathrm{BN}$ on CRS reduces the disorder of the system, thus producing an ordered arrangement of BN.

\section{Adsorption isotherm}

The efficacy of an inhibitor depends on its ability of adsorption onto a metal surface. Generally, it is accepted that the inhibitor molecule undergoes adsorption at the metal/solution interface and inhibits the corrosion process.

Attempts were made to fit the experimental data to various adsorption isotherms, including Temkin, Langmuir, Freundlich, Flory-Huggins and Bockris-Swinkels. But the best fit with Langmuir isotherm (Fig. 7) is according to the following equation [33]:

$$
\frac{C}{\theta}=\frac{1}{K_{a d s}}+C
$$


where $\mathrm{C}$ is the concentration of inhibitor, $\theta$ is the surface coverage and $\mathrm{K}_{\mathrm{ads}}$ the adsorption equilibrium constant. Using the values of $\mathrm{K}_{\mathrm{ads}}$, we can calculate thermodynamic parameters like $\Delta \mathrm{G}_{\text {ads }}, \Delta \mathrm{H}$ and $\Delta \mathrm{S}$, which are equally important in assigning a suitable mechanism for the adsorption of the inhibitor onto the metal surface. $\Delta G_{a d s}$ can be calculated according to equation (11) [34] and is represented in Table 5.

$$
K_{a d s}=\frac{1}{55.5} \exp \left(\frac{-\Delta G_{a d s}}{R T}\right)
$$

The value of $\Delta H$ and $\Delta S$ can be calculated using Vant-Hoff equation:

$$
\ln K_{a d s}=\frac{-\Delta H_{a d s}}{R T}+\frac{\Delta S_{a d s}}{R}+\ln \frac{1}{55.5}
$$

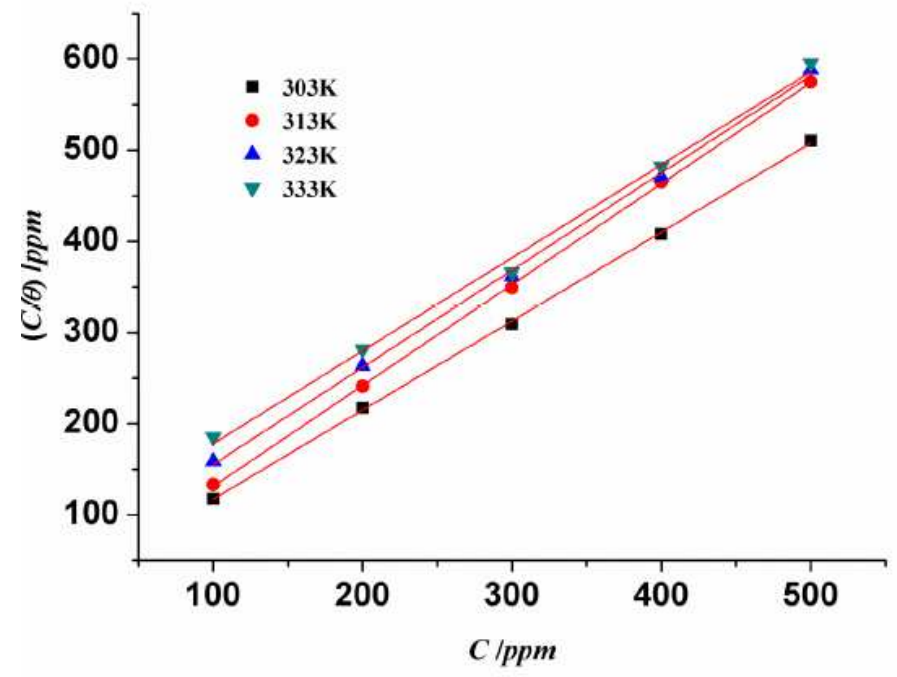

Figure 7. Langmuir adsorption of $\mathrm{BN}$ on the surface of $\mathrm{CRS}$ in $1 \mathrm{M} \mathrm{HCl}$ at various temperatures.

Table 5. Thermodynamic parameters for CRS in a $1 \mathrm{M} \mathrm{HCl}$ solution obtained from weight loss method.

\begin{tabular}{cccccc}
\hline $\begin{array}{c}\text { Temperature } \\
(\mathbf{K})\end{array}$ & $\mathbf{R}^{\mathbf{2}}$ & $\begin{array}{c}\mathbf{K}_{\text {ads }} \\
\left(\mathbf{M}^{\mathbf{1}}\right)\end{array}$ & $\begin{array}{c}\Delta \mathbf{G} \\
\left(\mathbf{k J m o l}^{\mathbf{1}}\right)\end{array}$ & $\begin{array}{c}\mathbf{\Delta \mathbf { H }} \\
\left(\mathbf{k J m o l}^{\mathbf{1}}\right)\end{array}$ & $\begin{array}{c}\mathbf{- \Delta \mathbf { S }} \\
\left(\mathbf{J m o l}^{\mathbf{1}} \mathbf{K}^{\mathbf{1}}\right)\end{array}$ \\
\hline 303 & 0.999 & 50890 & -37.42 & & \\
313 & 0.999 & 48900 & -38.55 & -41.1 & 77.54 \\
323 & 0.999 & 19968 & -37.38 & & \\
333 & 0.996 & 13161 & -37.38 & & \\
\hline
\end{tabular}

The graph (as shown in Fig. 8) of $\ln \left(\mathrm{K}_{\mathrm{ads}}\right)$ against $1 / \mathrm{T}$ gives a straight line with a slope of $-\Delta H / R$ and intercept equal to $[\Delta S / R+\ln (1 / 55.5)]$. All the values are mentioned in Table 5. The negative value of $\Delta \mathrm{G}_{\mathrm{ads}}$ suggests spontaneous adsorption of the inhibitor molecule on the steel surface. It is generally accepted that $\Delta \mathrm{G}_{\mathrm{ads}}$ values up to $20 \mathrm{~kJ} / \mathrm{mol}$ indicate physisorption, and that $40 \mathrm{~kJ} / \mathrm{mol}$ and above stand for chemisorption [35]. The free energy $\Delta \mathrm{G}_{\text {ads }}$ of $\mathrm{BN}$ comes around 37-39 $\mathrm{kJ} / \mathrm{mol}$, indicating that the comprehensive adsorption is accompanied by both physisorption and chemisorption. The negative values of $\Delta \mathrm{H}$ indicate that 
adsorption is an exothermic process [36], hence, the inhibition efficiency decreases with an increase in temperature.

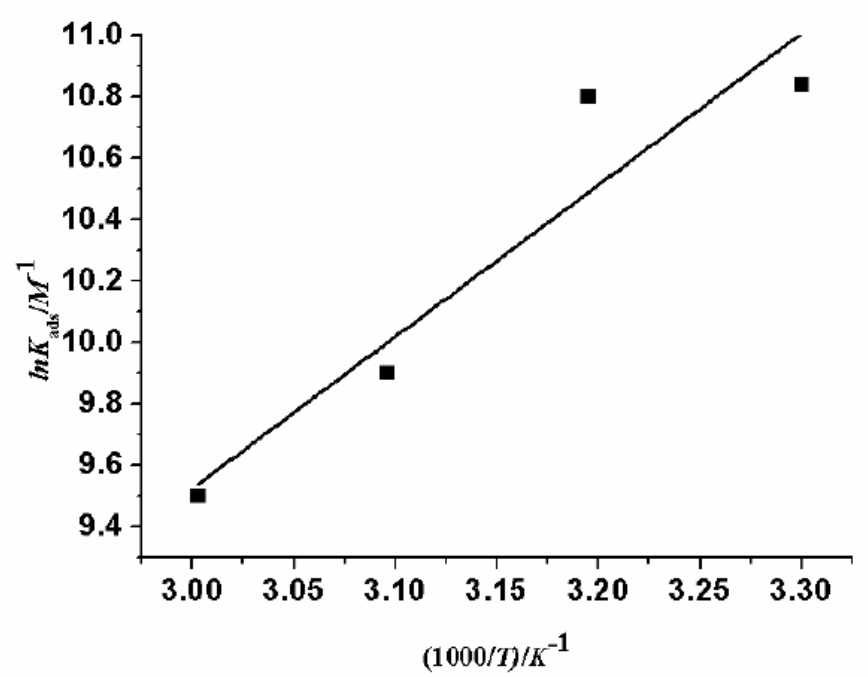

Figure 8. Relation between $\ln$ Kads against 1/T.

Generally, the exothermic process is attributed to either physisorption or chemisorption, while the endothermic process indicates pure chemisorption. Further, if the value of $\Delta \mathrm{H}$ is less than $41.86 \mathrm{~kJ} / \mathrm{mol}$, then it is physisorption, while for chemisorption, a $\Delta \mathrm{H}$ value is around $100 \mathrm{~kJ} / \mathrm{mol}$ [37]. $\Delta \mathrm{S}$ value indicates that the adsorption process is accompanied by an increase in entropy, which means that the adsorption process is a quasi- substitution process between the organic inhibitor molecule in solution phase and water molecule at the electrode surface [38], i.e., Org (sol) $+\mathrm{xH}_{2} \mathrm{O}_{(\mathrm{ads})} \leftrightarrow \mathrm{Org}_{(\text {ads })}+\mathrm{xH}_{2} \mathrm{O}_{(\mathrm{sol})}$. The organic molecule gets adsorbed onto the metal surface by replacing the water molecule, which means the gain in entropy is just because of an increase in the solvent entropy [39]. Increase in the solvent entropy means a decrease in the entropy of solute, which means an orderly arrangement of the inhibitor molecule onto the metal surface.

\section{Mechanism of adsorption}

The corrosion inhibition process mechanism of the inhibitor under consideration is of the adsorption type, as revealed by experimental studies. This adsorption is governed by many parameters including aromaticity, functional groups and presence of heteroatom. The BN inhibitor utilizes its COOR group and nitrogen containing pyridine heterocyclic; the R-group is composed of aromatic benzene, to bind the steel surface, thus acting as a barrier between steel and corrosive media and inhibiting the corrosion process of CRS in $1 \mathrm{M} \mathrm{HCl}$.

The anodic metal dissolution process involves the following reactions [40]:

$$
\begin{aligned}
& \mathrm{Fe}+\mathrm{Cl}^{-} \rightarrow\left(\mathrm{FeCl}^{-}\right)_{a d s} \\
& \left(\mathrm{FeCl}^{-}\right)_{a d s} \rightarrow(\mathrm{FeCl})_{a d s}+e^{-}
\end{aligned}
$$




$$
\begin{gathered}
(\mathrm{FeCl})_{a d s} \rightarrow\left(\mathrm{FeCl}^{+}\right)_{a d s}+e^{-} \\
\left(\mathrm{FeCl}^{+}\right)_{a d s} \rightarrow \mathrm{Fe}^{+2}+\mathrm{Cl}^{-}
\end{gathered}
$$

The cathodic hydrogen evolution progresses accordingly,

$$
\begin{gathered}
\mathrm{Fe}+\mathrm{H}^{+} \rightarrow\left(\mathrm{FeH}^{+}\right)_{a d s} \\
\left(\mathrm{FeH}^{+}\right)_{a d s}+e^{-} \rightarrow(\mathrm{FeH})_{a d s} \\
(\mathrm{FeH})_{a d s}+\mathrm{H}^{+}+e^{-} \rightarrow \mathrm{Fe}+\mathrm{H}_{2}
\end{gathered}
$$

The inhibitor molecule either remains the same, or it may get protonated in an acid solution [26]. Hence, the protonated BN gets attached to the positively charged anodic site of CRS through the bridging of $\mathrm{Cl}^{-}$ion. The inhibitor molecule directly attaches to the cathodic site through its hetero atom and, also, through donor-acceptor interactions using $\pi$-electrons of the aromatic ring, thus preventing both anodic and cathodic corrosion processes.

\section{SEM studies}

Surface morphology of CRS in a $1 \mathrm{M} \mathrm{HCl}$ solution in absence and presence of $500 \mathrm{ppm}$ of BN was studied, as shown in Fig. 9. In the absence of BN (Fig. 9a), the specimen is severely corroded creating deep cracks with an uneven surface. In the presence of $500 \mathrm{ppm} \mathrm{BN} \mathrm{(Figure} \mathrm{9b),} \mathrm{the} \mathrm{cracks} \mathrm{are} \mathrm{reduced} \mathrm{to} \mathrm{a} \mathrm{greater}$ extent. This indicates the protection of the $\mathrm{BN}$ molecule against corrosion.

(a)

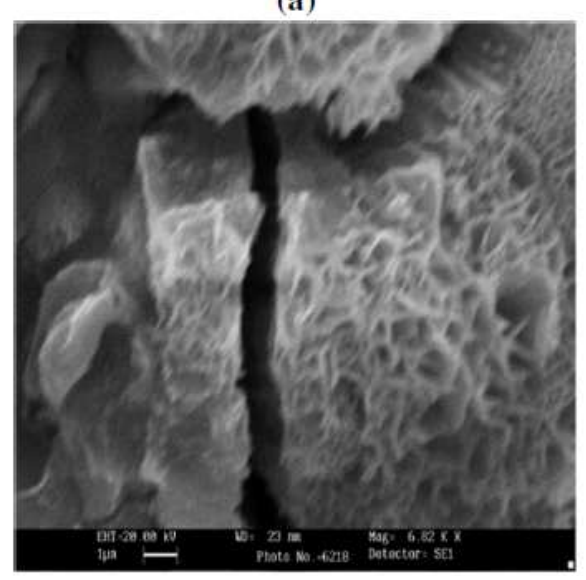

(b)

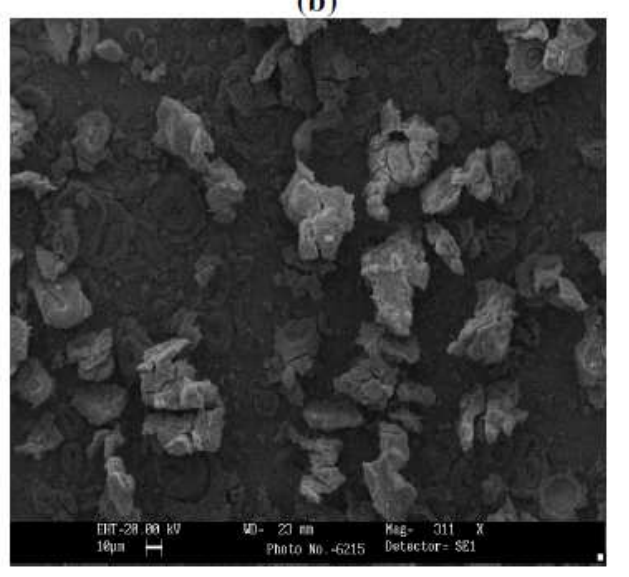

Figure 9. SEM images of CRS in a $1 \mathrm{M} \mathrm{HCl}$ solution both in absence (a) and presence (b) of $500 \mathrm{ppm}$ of $\mathrm{BN}$.

\section{Quantum studies}

Quantum chemical calculations helped us to correlate the corrosion inhibiting properties of an inhibitor molecule, with chemical and electrochemical method findings. With the theoretical prediction of the number of molecular parameters

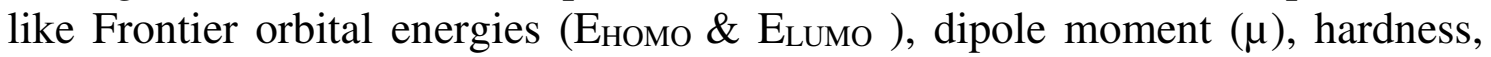
electronegativity $(\eta)$, ionisation energy (I), electron affinity (A), one can easily 
depict the nature of interactions between inhibitor and metal surface and, thus, possibly assign a suitable mechanism for inhibition.

The quantum calculations performed in gas phase using DFT method using B3LYP/6-311 G basic set and quantum chemical parameters are dipicted in the Table 6. Using frontier orbital energies $\mathrm{E}_{\text {HOMO }} \& \mathrm{E}_{\mathrm{LumO}}$, the interaction of the metal surface with the inhibitor molecule can be explained. The energy gap between LUMO and HOMO levels is another important factor in deciding the interaction. The inhibitor possessing lower energy produces good inhibition effficiency. A good inhibitor is one which has an ability to donate unoccupied porbital to the metal, and the capability of forming feedback bonds by accepting electrons from the metal [41-42].

Table 6. Quantum parameters as obtained from DFT method.

\begin{tabular}{|c|c|c|c|c|c|c|c|c|c|c|c|}
\hline $\begin{array}{l}\Delta E \\
(e V)\end{array}$ & $\begin{array}{c}\text { Еномо } \\
(\mathrm{eV})\end{array}$ & $\begin{array}{c}\text { ELUmo } \\
(\mathrm{eV})\end{array}$ & $\begin{array}{c}\text { I } \\
(\mathbf{e V})\end{array}$ & $\begin{array}{c}\mathrm{A} \\
(\mathrm{eV})\end{array}$ & $\begin{array}{c}\boldsymbol{\mu} \\
(\mathbf{D})\end{array}$ & $\underset{(\mathrm{eV})}{\chi}$ & $\begin{array}{c}\boldsymbol{\eta} \\
(\mathrm{eV})\end{array}$ & $\Delta \mathbf{N}$ & $\omega$ & $\mathbf{S}$ & $\begin{array}{l}\text { IE } \\
(\%)\end{array}$ \\
\hline 5.206 & -7.026 & -1.820 & 7.026 & 1.820 & 3.096 & 4.423 & 2.603 & 0.495 & 1.841 & 0.384 & 98.2 \\
\hline
\end{tabular}

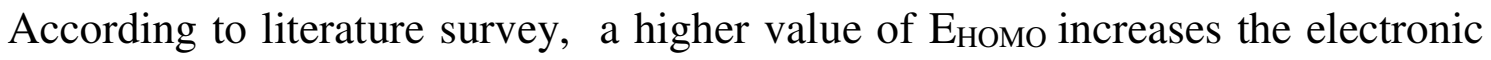
donating tendency of the inhibitor molecule. A lower value of ELUMO indicates the feed-back bonding tendency of the inhibitor. In general, a higher value of $\mathrm{E}_{\mathrm{HOMO}}$ and lower value of $\mathrm{E}_{\mathrm{LUMO}}$ symbolise a high inhibition efficiency of an inhibitor. In the case of the BN molecule (Fig. 10), HOMO is distributed over oxygen atoms and entire $\pi$-electrons of benzene; LUMO is distributed on the pyridine ring. Further, frontier orbital energies ( $\mathrm{E}_{\text {HOMO }} \& \mathrm{E}_{\mathrm{LUMO}}$ ) clearly indicate the electronic donating ability and feed back bond formation of the inhibitor. A lower value of dipole moment $(\mu)$ ranging between 3-5 favours the assembly of an inhibitor molecule on the metal surface [43], and also symbolises the hydrophobic character of an inhibitor molecule.

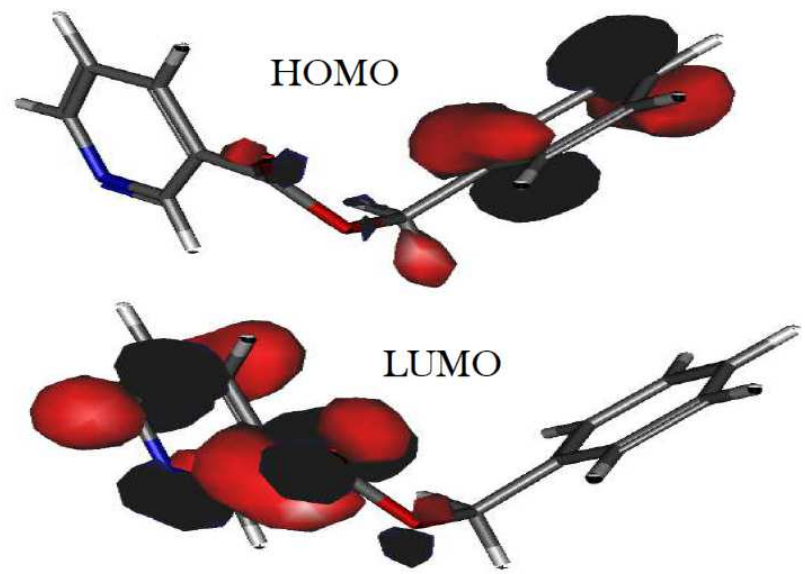

Figure 10. Pictorial representation of Frontier orbital distribution on BN.

For $\mathrm{BN}$, the dipole moment $(\mu)$ is 3.005 , hence, it favours the adsorption of the

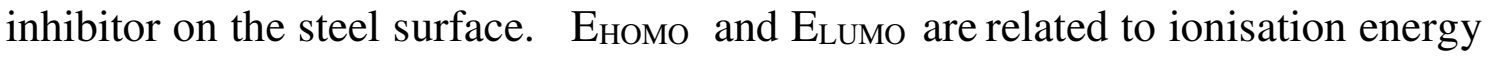
(I), electron affinity (A), absolute electronegativity $(\chi)$ and global hardness $(\eta)$, as: 


$$
\begin{gathered}
I=-E_{\text {номо }} \\
A=-E_{\text {LUмо }} \\
\chi=\frac{I+A}{2} \\
\eta=\frac{I-A}{2} \\
S=\frac{1}{\eta}
\end{gathered}
$$

The hardness and softness $(S)$ are measures of molecular stability and reactivity. A hard molecule has a larger energy gap and a soft molecule has a smaller energy gap [44].

$$
\omega=\frac{\mu^{2}}{2 \eta}
$$

This global electrophilicity index $(\omega)$ is a measure of change in energy due to the flow of electrons between donor and acceptor. This electrophilicity index gives the measure of stabilisation in the energy produced when the fraction of charge, $\Delta N$, is exchanged between inhibitor and metal surface [45], and is given by:

$$
\Delta N=\frac{\chi_{F e}-\chi_{i n h}}{2\left(\eta_{F e}+\eta_{i n h}\right)}
$$

where $\chi_{\mathrm{Fe}}$ and $\chi_{\mathrm{inh}}$ denote the absolute electro negativity of iron and of the inhibitor molecule, respectively; $\eta_{\mathrm{Fe}}$ and $\eta_{\text {inh }}$ denote the absolute hardness of iron and of the inhibitor molecule, respectively. In this study, the $\chi_{\text {inh }}$ and $\eta_{\text {inh }}$ values of the inhibitor are determined using the values of $I$ and $A$, and the theoretical value of $\chi_{\mathrm{Fe}}=7 \mathrm{eV} \mathrm{mol}{ }^{-1}$, and $\eta_{\mathrm{Fe}}=0 \mathrm{eV} \mathrm{mol}{ }^{-1}$ for the computation of the number of transferred electrons. Thus, the calculated value of $\Delta \mathrm{N}$ is 0.1926 , which clearly indicates the high inhibition efficiency of $\mathrm{BN}$, since $\Delta \mathrm{N}<3.6$ indicates the high inhibition efficiency with the electron donating tendency of the inhibitor molecule [44].

\section{Conclusions}

The results of experiments revealed that $\mathrm{BN}$ acts as a good inhibitor for CRS in a $1 \mathrm{M} \mathrm{HCl}$ solution. The BN molecule obeys Langmuir adsorption isotherm. Thermodynamic and activation parameters revealed a spontaneous and exothermic adsorption of the BN molecule. The obtained results from weight loss method are compatible with electrochemical results. Quantum studies support experimental findings. 


\section{Acknowledgements}

The authors are grateful to the University Grants Commission, New Delhi, Govt. of India, for providing financial assistance, and to the Department of Chemistry, Kuvempu University for providing lab facilities.

\section{References}

1. Fekry AM, Mohamed RR. Electrochim. Acta. 2010;55:1933.

2. Abd El Rehim SS, Hassan HH, Amin MA. Mater Chem Phys. 2003; 78: 337.

3. Bentiss F, Traisnel M, Chaibi N, et al. Corros Sci. 2002;44:2271.

4. Lebrini M, Lagrenee M, Vezin H, et al. Corros Sci. 2005;47:485.

5. Cano E, Pinilla P, Polo JL, et al. Mater Corros. 2003;54:222.

6. Moretti G, Guidi F, Grion G. Corros Sci. 2004;46:387.

7. Abd El-Maksoud SA. Int. J Electrochem Sci. 2008;3:528.

8. Sorkhabia HA, Shaabanib B, Seifzadeha D. Appl Surf Sci. 2005;239:154.

9. Hosseini MG, Ehteshamzadeh M, Shahrabi T. Electrochim Acta. 2007;52:3680.

10. Hassan HH, Abdelghani E, Amin MA. Electrochim Acta. 2007;52:6359.

11. Lebrini M, Lagrenée, Traisnel M, et al. Appl Surf Sci. 2007;253:9267.

12. Sudheer, Quraishi MA. Ind Eng Chem Res. 2014;53:2851.

13. Chakravarthy MP, Mohana KN. Int J Corros. 2013;Article ID 854781.

14. Chakravarthy MP, Mohana KN. ISRN Corros. 2014;Article ID 687276.

15. Hemapriya V, Savithri K, Parameswari K, et al. Int J Curr Res. 2014;6:4550.

16. Zhao J, Zhang N, Qu C, et al. Ind Eng Chem Res. 2010;49:12452.

17. Vinutha MR, Venkatesha TV. J Electrochem Sci Eng. 2015;5:209.

18. Emregul KC, Hayvali M. Mater Chem Phys. 2004;83:209.

19. Ali SA, El-Shareef, Al-Ghamdi RF, et al. Corros Sci. 2005;47:2659.

20. El Mehdi B, Mernari B, Traisnel M, et al. Mater Chem Phys. 2002;77:489.

21. Tao Z, Zhang S, Li W, et al. Ind Eng Chem Res. 2011;50:6082.

22. Solmaz R, Kardas G, Culha M, et al. Electrochim Acta. 2008;53:5941.

23. Singh AK, Quraishi MA. Corros Sci. 2010;52:152.

24. Kosari A, Momeni M, Parvizi R, et al. Corros Sci. 2011;53:3058.

25. Obot IB, Obi-Egbedi NO, Odozi NW, Corros Sci. 2010;52:923.

26. Obot IB, Obi-Egbedi NO. Curr Appl Phys. 2011;11:382.

27. Priya ARS, Muralidharan VS, Subramania A. Corrosion. 2008;64:541.

28. Pavithra MK, Venkatesha TV, Kumar MKP. Int J Electrochem. 2013;Article ID 714372.

29. Herrag L, Hammouti B, Elkadiri S, et al. Corros Sci. 2010;52:3042.

30. Behpour M, Ghoreshi SM, Soltani N, et al. Corros Sci. 2008;50:2172.

31. Ostavari A, Hoseinieh SM, Peikari M, et al. Corros Sci. 2009;51:1935.

32. El Ouali I, Hammouti B, Aouniti A, et al. J Mater Environ Sci. 2010;1:1.

33. Deng S, Li X, H. Corros Sci. 2010;52:3840.

34. Bentiss F, Lebrini M, Lagrenée M. Corros Sci. 2005;47:2915.

35. Noor EA. J Appl Electrochem. 2009;39:1465.

36. Li XH, Mu GN. Appl Surf Sci. 2005;252:1254.

37. Martinez S, Stern I. Appl Surf Sci. 2002;199:83. 
38. Cano E, Polo JL, Iglesia ALA, et al. Adsorp. 2004;10:219.

39. Ateya BG, El-Anadouli BE, El-Nizamy FM. Corros Sci. 1984;24:509.

40. Solmaz R. Corros Sci. 2010;52:321.

41. Khalil N. Electrochim Acta. 2003;48:2635.

42. Zhao P, Liang Q, Li Y. Appl Surf Sci. 2005;252:1596.

43. Cruz J, Martínez R, Genesca J, et al. J Electroanal Chem. 2004;566:111.

44. Karzazi Y, Belghiti MA, Dafali A, et al. J Chem Pharm Res. 2014;6:689.

45. V. S. Sastri VS, Perumareddi JR. Corrosion. 1997;53:617. 